\title{
SUBJETIVIDAD Y MUSICALIDAD: DE LA EDAD MEDIA AL RENACIMIENTO
}

\author{
Teo Sanz \\ Universidad de Burgos
}

\section{RESUMEN}

A través de un proceso de musicalidad y subjetivad, las ideas modernas sobre una nueva forma de crear, interpretar o escuchar la música que se desarrollaron a partir del siglo xvir se gestaron en la Edad Media y fueron evolucionando hasta su culminación en el Renacimiento. Este trabajo estudia cómo la música que acompaña a los textos adquiere una paulatina autonomía en el período referido. Analizar este fenómeno es fundamental para comprender el pensamiento musical de la Modernidad.

Palabras Clave: musicalidad, subjetividad, Edad Media, Renacimiento, música francesa, Estética de la Recepción.

\author{
SUBJECTIVITY AND MUSICALITY: FROM \\ THE MIDDLE AGES TO THE RENAISSANCE
}

\section{Abstract}

Many of the modern ideas regarding new ways of creating, interpreting or listening to music as developed from the $17^{\text {th }}$ century onwards were conceived in the Middle Ages through a process of musicality and subjectivity which reached its culmination in the Renaissance. This work studies how the music illustrating those ideas acquired a gradual autonomy in the mentioned period. The analysis of this fact is fundamental for the comprehension of musical thought in the Modern Age.

KeYwords: musicality, subjectivity, Middle Ages, Renaissance, French music, Reception Aesthetics. 
En estas líneas, me gustaría hacer una breve reflexión sobre cómo evolucionó el lenguaje musical desde la Edad Media hasta el Renacimiento y de qué manera las formas que adquiere ese arte influyen tanto en los ejecutantes como en los oyentes. En ese sentido, pondré el acento en un aspecto que me parece relevante: estudiar cómo la música vocal, a pesar de su vinculación con los textos, se va convirtiendo paulatinamente en un ente autónomo a través del enriquecimiento compositivo. Pero además, dentro de un enfoque propio de la Estética de la Recepción, considero importante distinguir el hecho de que la música, entendida como ente autónomo, nos envía un mensaje del cual nos apropiamos como sujetos receptores. Esta apropiación ha favorecido que a lo largo de la historia la propia musicalidad se haya ido modificando, generando nuevas formas de expresión, es decir, nuevos mensajes que han ido creando significados profundos, gozos inestimables y múltiples poéticas que podríamos definir como puramente expresivas, autónomas, aun sin el soporte de la literatura. Como escribió Franz Liszt en el siglo xix:

A medida que progresa la música instrumental, a medida que se desarrolla, que se libera de las trabas primeras, tiende a impregnarse de este ideal que ha marcado la perfección de las artes plásticas, a convertirse, no ya en una simple combinación de sonidos, sino en un lenguaje poético más apto quizá que la poesía misma para expresar todo lo que, en nosotros, rebasa los habituales horizontes, todo lo que elude el análisis, todo lo que se anuda a profundidades inaccesibles, a deseos imperecederos, a pensamientos infinitos ${ }^{1}$.

Con el fin comprender esa evolución estética de la música, es inevitable recurrir, al menos en Occidente, al quehacer musical de la Edad Media y del Renacimiento, ya que la búsqueda de las nuevas vías de expresión que emergen en los siglos que conforman este rico y largo período creativo hará posible que el lenguaje musical consiga cierta autonomía y un valor expresivo independiente. Podríamos decir, por lo tanto, que es en la Edad Media, y posteriormente en el Renacimiento, cuando se produce una revalorización de esa voluptuosa música lírica (poesía y música) que, como escribió Platón en La República, debía ser desterrada de la Polis, pues de lo contrario reinarían el placer y el dolor antes que la Ley. Recordemos que Platón adopta una doble actitud ante la música, por un lado la condena y, por otro, la exalta "como forma suprema de belleza y verdad $»^{2}$. Cuando la música produce placer, cuando nos deleitamos con ella y nos alejamos de la pura contemplación filosófica, esta ha de ser prohibida. Así, en el libro x de La República podemos leer: "solo deben admitirse en nuestro Estado los himnos a los dioses y las alabanzas a los hombres buenos. Sin embargo cuando recibes a la Musa dulzona, sea en versos

\footnotetext{
${ }^{1}$ Citado por J.P. Triay, Guía Universal de la Música. Colección Musica ma non Troppo, Barcelona, Robinbook, 2008, p. 214.

${ }^{2}$ E. Fubini, Estética de la música. Madrid, La Balsa de la Medusa, 2001, p. 63.
} 
líricos o épicos, el placer y el dolor reinarán en tu Estado en lugar de la ley y la razón que la comunidad juzgue siempre la mejor $»^{3}$.

Ya en los umbrales de la Edad Media, el pensamiento de san Agustín sobre la música ilustra las ambivalencias de la actitud cristiana frente a ese arte. San Agustín expresa de manera subjetiva, no sin cierto dramatismo, los argumentos a favor y en contra de la música. Esos motivos están expresados tanto en su tratado De Musica como en su autobiografía, las Confesiones. En esta última obra, el pensador recuerda las lágrimas que derramó el día de su conversión al oír los cantos de la iglesia, las cosas que se dicen con una voz cristalina y una adecuada modulación. Sin embargo, reconoce que cuando se siente más emocionado por el canto que por las cosas que se cantan, cree que merece un castigo y anhelaría no oír cantar. San Agustín se deja seducir por el arte de los sonidos, se siente fascinado por ellos, pero al mismo tiempo los rechaza. Existe en él una duda: desearía no oír cantar cuando el placer sensible de la música distrae al alma de la espiritualidad. No obstante, también reconoce que ese placer puede acrecentar el deseo de orar. La siguiente cita expresa de manera clara su concepción del arte musical y sus implicaciones psicológicas:

Así estoy vacilando entre el daño que del deleite de oír cantar puede seguirse y la utilidad que por la experiencia sé que puede sacarse; y más me inclino (sin dar en esto sentencia irrevocable ni definitiva) a aprobar la costumbre de cantar, introducida en la Iglesia, para que por medio del aquel gusto y placer que reciben los oídos, el ánimo más débil y flaco se excite y aficione a la piedad. Esto no quita que yo conozca y confiese que peco y que merezca castigo, cuando me sucede que el tono y canto me mueve más que las cosas que se cantan, y entonces más quisiera no oír cantar. Ve aquí el estado en que me hallo al presente en cuanto a esto ${ }^{4}$.

San Agustín encarna perfectamente la ambigüedad entre la música puramente pensada, razonada teóricamente, y la música como placer. Esa dualidad frente al hecho musical planeará, sin duda, sobre el pensamiento medieval y llegará no solo hasta el Renacimiento, sino incluso más lejos.

Tal vez sea a partir del año mil cuando realmente se comience el estudio de la música como arte independiente. A ello contribuyó el que está considerado como uno de los grandes teóricos medievales: Guido de Arezzo (991-1050). Este músico dedicó su atención a los problemas técnicos del arte y a las cuestiones pedagógicas. A él le debemos el nombre de las notas actuales. Además, Arezzo ya habla abiertamente de sentir emoción en el canto. Así, en su obra Micrologus, piensa que la música debe adecuarse a los temas del texto. A pesar de aceptar esa sumisión, estima que

3 Platón, Diálogos IV. República. Madrid, Gredos, 1988, 607a, p. 476.

${ }^{4}$ Agustín de Hipona, Confesiones. Madrid, Ed. digital basada en la de Espasa Calpe, 1983, p. 265. 
«el efecto del canto deberá imitar lo que sucede; así en la tristeza, los neumas serán graves; en la paz afables; en la fortuna exultantes....15.

Será precisamente en torno al año mil cuando encontremos de manera embrionaria los ensayos de polifonía que más tarde van a adquirir una importancia notoria en la evolución de la música y, por consiguiente, en la percepción que se irá teniendo de la misma. Poco a poco, en el devenir de la Edad Media, se irán dejando de lado las cuestiones especulativas y se pondrá el foco en los problemas tangibles que conllevará la práctica polifónica. Es interesante constatar, sin embargo, cómo inicialmente el concepto de belleza seguirá inspirándose en los cánones griegos porque justamente se basa en la realización de la armonía. Pero la noción de armonía también se irá modificando en la medida en que se aleja de las categorías matemáticas o metafísicas y se convierte en algo más prosaico. El concepto de Belleza terminará por ser algo terrenal, existirá para el placer de los sentidos.

Otro hecho a resaltar es que, a lo largo de la Edad Media, la dimensión de la subjetividad comienza a ser igualmente tenida en cuenta en los tratados musicales. Las cuestiones técnicas relativas a la consonancia y la disonancia (diabolus in musica en el intervalo de fa a si) se estudian en términos que hoy calificaríamos de psicológicos, abandonando las elucubraciones matemáticas. Ya en el siglo xiv se hablará abiertamente de la música como algo natural.

Enrico Fubini ${ }^{6}$ se refiere al monje inglés Simon Tunsted, fallecido en 1369, como uno de los pensadores que consolida, esta forma de concebir la música. En efecto, este monje franciscano, filósofo y músico, escribió un tratado, Quatuor principalia musicae, en el que ya habla de la música como algo natural, algo que existía antes que nada, antes que la ciencia musical. En ese texto, podemos leer que los hombres utilizan de manera natural los cantos. Además, subraya cómo, aun sin conocer la técnica, cantan juntos con increíble suavidad. Así, considera que la música forma parte de la naturaleza humana y que ha existido en todas épocas. Además, sostiene que todo el mundo se sirve de ella: niños, jóvenes, viejos y mujeres, al tiempo que gozan de las melodías con natural placer: «Parece claro, por tanto, que la música está tan estrechamente ligada a la naturaleza del hombre que, aunque lo quisiéramos, no podríamos existir sin ella» ${ }^{7}$. Esta afirmación es muy moderna para la época. Tusnted se adelanta a los planteamientos sobre la música que, por ejemplo, el filósofo de las Luces Jean-Jacques Rousseau hiciera cuatro siglos más tarde. Recordemos que en sus disputas con Jean-Philippe Rameau, Rousseau siempre sostuvo que la música es el origen del lenguaje, que «Nunca hubo antes más música que la melodía, ni otra melodía que no fuese el sonido variado de la palabra; los acentos formaban el canto, los cantos formaban la medida, y se hablaba tanto por medio de los sonidos

5 G. D’Arezzo, Micrologus, citado por O. Cullin, Breve historia de la música en la Edad Media. Barcelona, Paidós, 2005, p. 41.

${ }^{6}$ E. Fubini, op. cit. (2001).

7 S. Tunsted, Quatuor principalia musicae, citado por E. Fubini, op.cit, p. 88. 
como por medio del ritmo y las articulaciones de la voz. Decir y cantar fueron en el pasado una misma cosa».

¿Cómo evolucionó esa subjetividad a partir del canto gregoriano y posteriormente en la música polifónica? En el canto gregoriano y su sistema modal ya encontramos algún espacio para la expresión libre de la subjetividad. En ese sentido, el ritmo sin medida se presta a la expresividad emotiva del yo. En su primera época el canto era llano, pero se fue enriqueciendo y, en el siglo XI, comienza a usarse el estilo silábico. Los tropos ejemplifican esa nueva vía de expresión y hoy en día están considerados como uno de los fenómenos musicales más notables de la música de la Edad Media. Como es sabido, esta forma musical consiste en añadir notas y sílabas al texto de base. Esto significa que frente a la monodia religiosa fija, que no permitía ningún desliz, ni toleraba las modificaciones, la tendencia natural a la expresión busca la creatividad y la emoción en la prolongación, por otra parte muy musical, de las sílabas, las cuales, a su vez, contienen una musicalidad propia que se aleja, en cierta medida, del texto y de su semanticidad. Esta práctica es una muestra del impulso creativo de los monjes y de los clérigos. Poco a poco, esas piezas se fueron independizando dando lugar a nuevas formas compositivas que salieron del ámbito puramente religioso para entrar en el ámbito de la canción popular. Como señala Jacques Chailley, los tropos

Terminarán por convertirse en alegres estrofas de corte incisivo, en versos cortos llenos de asonancias y de aliteraciones, en frases musicales francas y simétricas, a partir de los cuales se reconstituye sin esfuerzo la vía que conduce directamente a nuestra canción popular francesa. Es igualmente a partir de los tropos, cuando éstos comienzan a usar la lengua vulgar, de donde nacerá en gran parte, en el siglo XII, la poesía lírica de los trovadores?.

En efecto, este mismo fenómeno de expresividad intensa se dará igualmente en la música sencilla, es decir, la música profana, que nace con las lenguas vulgares. A través de estas lenguas, la gente adquiere más conciencia de lo subjetivo y de lo individual. Por ese medio expresaron con mayor énfasis sus deseos y aspiraciones más allá de la religión. La música de los trovadores y los troveros, arte profano, pero igualmente monódico, es el arte por excelencia del tropator, del hacedor de tropos. Estos creadores se sirven de composiciones melódicas que han existido desde tiempos inmemoriales. Es lo que el musicólogo serbio Rudolph Réti $(1885-1957)^{10}$ llama "tonalidad melódica», es decir, una repetición de secuencias melódicas y de modalismos prearmónicos que existen en el folclore popular, especialmente del este de Europa, en ritos babilónico-judíos y también en el canto llano. Es muy interesante

${ }^{8}$ J.J. Rousseau, Essai sur les origines des langues. CEuvres Complètes V. París, La Pléiade, 1995 , p. 411.

9 J. Chailley, L'École musicale de Saint-Martial de Limoges. París, Les Livres Essentiels, 1960, pp. 65-66.

${ }^{10}$ R. Reti, Tonality in Modern Music. Nueva York, Collier Books, 1962, p. 32. 
constatar cómo esta técnica se utilizó de nuevo en el siglo xx, especialmente para poner en duda la tonalidad y la armonía clásicas. Erik Satie o Claude Debussy, entre otros, compondrán obras siguiendo esa técnica.

La música de los trovadores y los troveros supone un medio ideal para expresar el amor, para cantar a la naturaleza, etc. Se trata de la expresión de una subjetividad que, de manera natural y sencilla, proclama los sentimientos sin necesidad de sofisticaciones armónicas. Los trovadores y los troveros practican la canción, una forma que siempre ha existido en la evolución de la música occidental. Son obras con esquemas rítmicos sencillos y de gran expresividad emocional. Para expresar esa subjetividad, las formas musicales utilizadas muestran cambios con respecto al gregoriano: un ritmo más marcado y mucho más variado, con fuerte dependencia del contenido emocional del texto: alegre, triste, amoroso, guerrero, etc. Estas formas profanas no siempre son a capella, ya que también se acompañan de instrumentos como laúdes, arpas, violas u otros de percusión dedicados a marcar el ritmo.

Un aspecto interesante a tener en cuenta a la hora de hablar de subjetividad en el arte de los trovadores y los troveros es la cuestión de la notación. A este respecto, Michel Zink considera que los cancioneros de los troveros del norte de Francia contienen más notaciones musicales que los cancioneros de los trovadores. ¿Se podría decir entonces que el norte, de lengua d'oil, habría otorgado más importancia a la cuestión musical que el Midi, de lengua d'oc? Zink considera que no se podría dar una respuesta definitiva a esta cuestión, pero lo que sí es indudable, a su entender, es que esas anotaciones permiten que el público se apropie del poema, dado que «la melodía invita al que se sirve del manuscrito a abandonar su papel pasivo de simple receptor del poema en favor de un papel activo de intérprete. Así, este, al cantar, hace suyas las palabras del poema y se identifica con la subjetividad que en él se expresa ${ }^{11}$.

Casi de manera paralela a esas manifestaciones musicales monódicas, va a tener lugar otro fenómeno musical de vital importancia en la Edad Media y, a la postre, en la historia de la música occidental. Me estoy refiriendo al nacimiento de la polifonía, es decir, a un tipo de música en la que varias voces suenan simultáneamente, de manera vertical, y que más tarde, sin perder del todo esa verticalidad, tenderá a ser más contrapuntística. La analogía entre el florecimiento de la arquitectura gótica de los siglos XII y XIII y los melismas es manifiesta. Los colores sonoros, las sinestesias, tan bien expresadas poéticamente en el siglo XIX por Baudelaire y Rimbaud, son el brillo de las vidrieras de las catedrales, el impulso ascensional de los pilares y las columnas. En ese marco resuena con fuerza dionisíaca la música teñida de los nuevos ritmos. Destaca en este aspecto el músico de la escuela de Notre-Dame Perotino (1155 (60)-1230). Sus organa a cuatro voces, con una rítmica incesante y un cruzamiento de voces hasta entonces inédito, consiguen que el oyente alcance un goce estético notable. Tenemos aquí un ejemplo manifiesto de cómo la escritura

${ }^{11}$ M. ZINK, «Musique et subjectivité. Le passage de la chanson d'amour à la poésie personnelle au XIII ${ }^{\mathrm{ème}}$ siècle». Cahiers de civilisation médiévale, vol. 25, núm. 99-100 (1982), 225-232, p. 226. 
musical y su ejecución pueden acrecentar el éxtasis del yo creador y del que disfruta de esa creación.

Dentro de la polifonía medieval se suelen distinguir tres períodos: el nacimiento de esta forma creativa, en torno al siglo Ix; el Ars Antica, que se desarrolla fundamentalmente en siglos XII y xIII; y el Ars Nova, que tiene su apogeo a partir del siglo xIv.

Por lo que respecta al primer período, no hay uniformidad entre los musicólogos. Estudios recientes sostienen que la polifonía de la Europa cristiana no es más que la culminación de una evolución que se remonta a épocas primitivas, ya que la música nunca ha dejado de ser polifónica. Sea como fuere, la realidad nos dice que los primeros ensayos conocidos de la polifonía occidental tienen lugar en torno al siglo IX y se denominan organum o diafonía. En esa forma las voces se mueven en un rígido paralelismo. Más tarde, acercándonos al siglo $\mathrm{x}$, las dos voces se moverán por movimientos contrarios (discantus) y posteriormente las voces evolucionarán en intervalos de terceras y sextas (gymel y fabordón), un poco como en los dúos populares actuales ${ }^{12}$. Se cree que los orígenes del canto a varias voces fue inventado por un monje, Hucbald de Saint-Amand (840-930), con gustos extravagantes y creador del organum con tintes cacofónicos. En efecto, en el siglo Ix, este monje franco-flamenco, de la Abadía de Saint-Amand, en Tournai, ya se refiere en su tratado Musica Enchiriadis a la unión de voces diferentes. En su obra defiende que doblando la melodía mediante una segunda voz a un intervalo constante distinto de la octava se obtendría una melodía de sonido agradable. Pero donde mejor se manifiesta la libertad del yo que canta es cuando se quiere que las voces sean paralelas sirviéndose de los intervalos de cuarta. En ese caso, se chocaba con sonoridades desagradables para el oído, como la cuarta aumentada, denominada tritono o también diabolus in musica (fa-si), al que ya me referí con anterioridad. Lo interesante en este caso es que Hucbald, más allá de las cuestiones técnicas, ya medita sobre el efecto que tiene la música en el ser humano, sobre su carga emocional, porque es necesario que la canción imite el carácter emocional de las cosas.

Será en el siglo XII cuando la polifonía se consolide, sobre todo a partir del momento en el que la importancia cultural de París cobra relevancia. El estilo musical que nace en el corazón de esa ciudad gozará de gran prestigio y se va a propagar por toda Europa. Es lo que se conoce como Ars Antica. La segunda mitad del siglo XII está marcada por una poética de la luz que conlleva la reflexión poética de Suger pero, como declara Georges Duby: «la estética que suscita no se limita solo, sin embargo, a la arquitectura» $»^{13}$. Una afirmación muy cierta porque los grandiosos organa a cuatro voces de Perotino, director de música en Notre-Dame desde finales del XII hasta 1236, destinados a las fiestas navideñas, son un ejemplo de luminosidad que admite formas vocales liberadoras y exultantes. Estarían muy en consonancia con

${ }^{12}$ Cf. M. Pérez, El universo de la música. Madrid, Musicalis, 1998, pp. 166, 170.

13 G. Duby, Le Temps des Cathédrales. L'Art et la société 980-1420. París, Gallimard, 1976, p. 126. 
la idea del abad de Saint-Denis, Suger (1081-1151), de introducir piedras preciosas en la decoración de las catedrales de manera que su brillo se convirtiera en un haz de luz que convergiera en el coro, el principal lugar del culto divino. Suger se siente transportado por la belleza de la casa de Dios. Esa belleza se acrecienta aún más con el brillo de las gemas multicolores. En su éxtasis, Suger nos ofrece reflexiones apasionadas sobre las virtudes sagradas:

Tengo la impresión de verme a mí mismo residir en otra realidad, en alguna región extraña del universo que no ha existido con anterioridad ni en el cuerpo terrestre ni en la pureza del cielo, y que por la gracia de Dios, puedo ser transportado de manera anagógica desde aquí abajo hasta el mundo más elevado ${ }^{14}$.

Pero retomemos la evolución de las formas musicales de ese período. Es curioso observar cómo los avances de un momento concreto pueden retroceder según camina la historia. Así, contrariamente a esa temprana liberación de la música, la forma motete que sucede al organum basa su estética en la adición de varios textos. De esta manera, el lenguaje se convierte en una marca de domino del intelecto, se vuelve a una era de la razón que modela la música y, por consiguiente, la actitud del que la oye. Así, se pone un límite al goce por medio de la primacía absoluta de la palabra divina.

A pesar de esos retrocesos, sobre todo en el ámbito religioso, la música va a seguir evolucionando. A finales del siglo XIII (1270) y principios del XIV (1320) tendrán lugar transformaciones importantes. Podríamos decir que poco a poco irá surgiendo un movimiento musical que se caracteriza por la complejidad de la escritura y por una enorme variedad rítmica. El motete del siglo XIII se verá eclipsado por nuevas estéticas que están al servicio del ser humano. La música va a ser un testigo importante de estas transformaciones. Poco a poco la técnica musical pierde sus simbolismos teológicos y buscará el efecto puramente sonoro que lleve al gozo sensual de la música pura. Se enriquecerán los ritmos y nacerán nuevas armonías. Es lo que se conoce como el Ars Nova. Muchos elementos de esta forma de crear encajan perfectamente en el tema que estoy abordando aquí: la subjetividad y la musicalidad. Por primera vez la individualidad del compositor va a tener una gran relevancia. Del anonimato de épocas precedentes, se empieza a saber quién compone. De esta manera, se pone de manifiesto la individualidad y la originalidad.

Sin embargo, hay muchos más aspectos que reseñar al respecto. Pensemos en la importancia del cuerpo humano y su relación con el ritmo. Ahora, se dará una igualdad entre el ritmo binario (simetría del cuerpo humano) y el ternario, teológico, propio de los siglos precedentes. Por ello, también se reconocerá la notación musical y los distintos valores que posee cada nota. Esa mayor riqueza y complejidad de la escritura conllevará una nueva manera de gozar de la música. Frente a los primeros paralelismos de voces se extiende el uso de la imitación y el canon. Se puede decir

${ }^{14}$ Ibidem, pp. 126-127. 
que la polifonía a tres y cuatro voces se generaliza. De la misma forma, la melodía se enriquece, será más florida. La autonomía de la música que proporciona placer por sí misma se extiende igualmente a la música profana, en la que se introducen danzas y temas instrumentales.

La historia de la música está llena de disputas estéticas. Tal vez se podría decir que los debates entre los partidarios del Ars Antica y del Ars Nova, representaron la primera disputa estético-filosófica en Occidente, tanto en lo que se refiere al gusto como a la ideología. Para ilustrar esta teoría, Fubini ${ }^{15}$ se refiere a la famosa bula con la que Juan XXII condenaba el Ars Nova porque la complejidad polifónica, el cruce de las voces, lleva al oyente a un goce autosuficiente. Para Juan XXII, esa música borra la sencillez y los equilibrios del canto llano. Es una música que embriaga los oídos y no se preocupa de las almas. Es interesante constatar igualmente cómo el pontífice ya se refiere a la gestualidad que imita lo que se toca de modo que se olvida la devoción. Juan XXII considera que esa relajación debía ser evitada. Lo cierto es que va a ocurrir todo lo contrario, las nuevas formas de disfrutar la música adquirirán una gran relevancia a lo largo de los siglos posteriores. Quizá sea con Diderot en el siglo XVIII cuando se exprese por primera vez en la ficción los efectos de la música, el éxtasis que esta produce. En efecto, en su obra El sobrino de Rameau, observamos cómo el personaje que se denomina justamente "el sobrino» recurre, en su paroxismo, a la mímica para sustituir al lenguaje convencional ofreciéndonos el sonido y el espectáculo de toda una orquesta:

Con las mejillas infladas e hinchadas, y un sonido ronco y sombrío, imitaba los cornos y las tubas; producía un sonido brillante y nasal para los oboes; precipitaba la voz con una rapidez increíble para los instrumentos de cuerda, buscaba los sonidos más aproximados; silbaba como las pequeñas flautas, arrullaba como las flautas traveseras; gritaba, cantaba, se agitaba como un loco... ${ }^{16}$.

En el período del Ars Nova, la música ya empieza a ser considerada como un fin en sí mismo. La música adquiere una cierta autonomía y se comienza a valorar el aspecto auditivo de la misma. A modo de ejemplo, veamos de qué manera dos músicos franceses fueron pioneros en esta tarea. El primero de ellos, Philippe de Vitry (1291-1361), está considerado como el gran teórico del ritmo. Hasta principios del siglo XIv, el ritmo tenía una gran dependencia de los esquemas del lenguaje. Vitry crea en Francia un sistema nacional del ritmo que se ha convertido en uno de los hitos de la historia de la música, sobre todo porque, gracias a sus teorías, este arte gana en musicalidad y al mismo tiempo se independiza del rígido control prosódico. El ritmo predomina con sus líneas melódicas estilizadas que poseen un valor expresivo por sí mismas sin necesidad de recurrir a los contenidos afectivos

${ }^{15}$ E. Fubini, La estética musical desde la Antigüedad hasta el siglo XX. Madrid, Alianza Música, 1988, pp. 115-116.

${ }_{16}$ D. Diderot, El sobrino de Rameau. Edicción de Carmen Roig, traducción de Dolores Grimau, Madrid, Cátedra, Letras Universales, 2005, pp. 141-142. 
del texto. Como escribe Lewis Rowel, Vitry «desarrolló una jerarquía más alta de compases, divisiones y subdivisiones de compases, agrupamientos de compases, de frases y niveles arquitectónicos más altos» ${ }^{17}$. Philippe de Vitry escribió igualmente la música de los motetes que ilustran el Roman de Fauvel ${ }^{18}$. Recordemos que este poema alegórico es un ejemplo de estudio de las costumbres de la época. Fue escrito por Gervais de Bus y Chaillou du Pestain, quienes dan voz a un asno, Fauvel, cuyo nombre es un acróstico de los principales vicios del mundo: Flatterie (Adulación), Avarice (Avaricia), Vilenie (Villanía), Variété (Inconstancia), Envie (Envidia), Lâcheté (Cobardía). La música es muy variada y casi siempre de autores desconocidos. No obstante, se sabe que los motetes polifónicos fueron compuestos por Vitry. Su función consiste en interpelar al texto y algunos de ellos, aunque no todos, son un buen ejemplo de esa libertad rítmica que caracteriza al Ars Nova.

Si Vitry sobresale como músico y por sus tratados teóricos, su discípulo, Guillaume de Machaut (1300-1377), poeta y compositor, lleva a cabo una transformación de la música polifónica en el plano compositivo. Sus creaciones polifónicas contienen tanto música profana como religiosa. Machaut es el máximo representante en la Europa del siglo XIV de este arte «vanguardista». Sus innovaciones están relacionadas con fórmulas rítmicas inéditas. Machaut pasó a la historia por ser el autor de una misa completa, la "Misa de Nôtre-Dame», considerada como una joya de la polifonía. Es uno de los primeros en servirse de los isorritmos, es decir, de la persistencia del mismo ritmo en una voz, aunque las notas cantadas fueran distintas. Pero además de la misa citada, Machaut escribió 23 motetes y una gran variedad de canciones polifónicas profanas que elaboró a partir de las formas con estribillos como el virelai, el rondeau o la balada. Por lo que se refiere a la teoría de la subjetividad que rige estas líneas, quiero señalar que, a pesar de que su música profana sigue más de cerca la articulación sintáctica del texto, las innovaciones melódicas de Machaut fortalecen la expresión. Pero al mismo tiempo que esto sucede, se va a dar otro fenómeno relativo a la expresión lírica del yo: el nacimiento de una poesía que ya no es lírica, sino personal, que dramatiza el yo ${ }^{19}$. En ese sentido, la forma Dit, un poema no destinado a ser cantado, creada por Machaut, renunciaría, buscando otras formas de la subjetividad, a la melodía de la canción. Tal vez esto se deba a que la complejidad armónica de la polifonía conlleva que la melodía sea autosuficiente en su expresión lírica y ya no necesite de manera tan imperiosa el soporte textual.

En el siglo xv prosiguen las experimentaciones polifónicas que en algunos casos llegan a complicaciones extremas. Mucho se ha hablado de la artificiosidad del siglo XV, sobre todo cuando se hace alusión a los músicos de las nuevas naciones hegemónicas en el arte polifónico: Inglaterra, Borgoña y Flandes. En Holanda, se extendió de manera notoria el canon imitativo. ¿En qué consistía? La melodía que canta una voz era imitada total o parcialmente por las otras voces. Mientras esas voces

\footnotetext{
${ }^{17}$ L. Rowell, Introducción a la filosofía de la música. Madrid, Gedisa, 1990, p. 102.

${ }^{18}$ Le Roman de Fauvel. París, Coll. Lettres Gothiques, Le Livre de Poche, 2012.

${ }^{19}$ M. ZINK, op. cit, p. 231.
} 
imitan, la melodía primera sigue su curso inalterable a la vez que las restantes voces van imitándola. Pero esta imitación se podía complicar más. A veces era exacta, pero otras imitaciones eran por aumentación, aumentando los valores, o por disminución, disminuyendo los valores a la mitad. También existe la forma en espejo, por movimiento contrario, con la partitura al revés o incluso de atrás hacia delante. Por esa razón, a finales del siglo XV se observa una reacción frente a las sofisticaciones, dado que estas son "un obstáculo para conmover el ánimo y provocar afección alguna», como bien lo señala, ya en el siglo xvi, Vincezo Galileo ${ }^{20}$.

Pero hay un hecho cierto: en la segunda mitad del xv ya estamos muy lejos de las argumentaciones teórico-matemáticas propias de ciertas doctrinas medievales platónicas. Como señala Johannes Tinctoris en su obra Proportionale musices, publicada en torno a 1476: «las posibilidades de nuestra música han crecido tanto que parece ser un arte nuevo, si se puede decir así ${ }^{21}$.

En ese momento es cuando la armonía se define casi por completo en términos subjetivos. La armonía es sinónimo de placer, de un placer producido por los sonidos adecuados. Se habla de consonancias y disonancias, pero siempre en clave subjetiva. Una es dulce y agradable para el oído, la otra es una ofensa que altera.

Es probable que Josquin Desprès (hacia 1440-1521) sea el que culmine todas las tendencias medievales. Este gran músico logra un equilibrio de fuerzas entre la verticalidad (armonía) y la horizontalidad (contrapunto). Sin embargo, conviene matizar que Josquin encarna también las ideas del Renacimiento y la Reforma, que otorgaban cada vez más importancia a la palabra. Aun así, este inmenso compositor es el creador de un tipo de canción que libera las formas fijas de la poesía, de ahí que se puedan repetir palabras o grupos de palabras con una mayor libertad en las relaciones del verso con la melodía. Además de utilizar las cuatro voces, Josquin innova llegando a introducir hasta cinco o seis voces. Se trata de un músico muy original que ornamenta espontáneamente las melodías que él mismo cantaba mientras componía porque así lograba que despertara la imaginación. De este modo, sienta las bases de una interpretación flexible de la música que él mismo creaba. Josquin practica lo que hoy podríamos denominar una poética aperta, o sea, una estética que deja espacios para que la subjetividad se exprese también en la interpretación, lo que sin duda tiene una gran importancia a la hora de que los oyentes se acerquen a la música de manera más imaginativa. Más tarde, en pleno siglo xvi, Rolando de Lassus (1532-1594) escribirá motetes con 12 voces. Lassus es un claro ejemplo de cómo la polifonía llega a las cumbres más altas del arte. Su música tiene efectos inesperados. Las líneas melódicas de sus obras son muy elaboradoras, poseen una gran riqueza expresiva y están sembradas de largos pasajes y también de silencios. Su estilo es ya muy moderno. Lassus se mueve con soltura en varios registros, pasando continuamente de la escritura polifónica a la vertical o armónica. Pero su música estará siempre al servicio de los textos, aunque hay que decir que se atreve a elegir

20 E. Fubini, op. cit. (1988), p. 100.

21 Citado en L. Rowell, op. cit, p. 104. 
aquellos que nunca habían sido puestos en música. Su polifonía está dedicada a expresar el contenido emocional y pictórico del texto.

A la vista de estos ejemplos concretos, se puede observar de qué manera la música del Renacimiento recoge muchas de las ideas que se intuyeron y, en cierta medida, se plasmaron, en la Edad Media. Ahora las innovaciones que se incorporan hacen posible que la música se convierta cada vez más en un arte autónomo. Tinctoris escribe otra obra, titulada Complexus effectuum musices, en la cual enumera los veinte efectos que produce el arte de los sonidos en el ser humano. Buscando un punto de vista puramente emotivo, es pertinente decir que a este tratadista ya solo le interesa «la música de los instrumentos, la que resuena y es analizable, por tal motivo, a través de los efectos que produce» ${ }^{22}$.

Es reseñable, pues, destacar cómo en ese momento se concretizan las líneas individuales estructuradas por rítmicas independientes. De este modo, no solo las estructuras son más o menos verticales, sino que la música fluye, es «devenir»y está pensada para ser disfrutada y percibida por sí misma apelando directamente a los sentidos. Creatividad e imaginación forman parte de la mueva teoría estética. La individualidad creativa da lugar a la noción de estilo personal. De esta forma, el objetivo principal del arte musical es la búsqueda de la expresión individual. El compositor transmite sus sentimientos para disfrute de los oyentes que se acercan a su obra. Se completa así el círculo de la subjetividad y de la musicalidad en un contexto de modernidad pragmática comunicativa.

Para concluir, se podría decir que, desde ciertas formas del gregoriano hasta los ensayos polifónicos medievales más sofisticados, a veces casi matemáticos, hay un intento, quizá en un primer momento inconsciente, de mostrar el sentido de la autonomía de la música y de gozar de la misma. No podemos obviar, como certeramente señala Fubini, que existe un gran placer en cantar juntos, por un lado, y el texto litúrgico como hilo conductor, por otro. Ese modelo de ejecución y disfrute de la música es característico de la música religiosa de la Edad Media. Ahora bien, más adelante, a medida que se va avanzando hacia el Renacimiento, se abren nuevos horizontes. Se puede contemplar una paulatina laicización de la música y esta, con sus formas profanas impetuosas y con la separación cada vez mayor entre quien la ejecuta y la escucha, se convierte en un verdadero «instrumento emotivo capaz de mover los afectos, de conmover y de estremecer las cuerdas del ánimo humano» ${ }^{23}$.

Es cierto que a medida que transcurren los siglos se da en la polifonía una prevalencia cada vez más notoria de los criterios de la música independientemente de su relación con la palabra. La estética musical renacentista se hace eco de esos logros expandiendo esa técnica por medio de creaciones cuyo estilo musical es cada vez más personal. Tanto en la creación como en la recepción, el camino hacia la diversidad se despeja con paso firme. Frente a cánones absolutos, el concepto de belleza será cada vez más subjetivo. Así, podemos deducir que el yo, el sujeto oyente, es capaz de

22 E. Fubini, op. cit. (2001), p. 123.

23 E. Fubini, op. cit. (1988), p. 132. 
disfrutar con más intensidad de una música cuya estructura puede ser matemática, pero capaz, como diría posteriormente Leibniz, de darnos un placer supremo, sobre todo si se mezcla la consonancia con la disonancia ${ }^{24}$.

En suma, es de gran importancia, para comprender la estética musical en su conjunto, establecer que estas ideas basadas ya en una nueva forma de crear, interpretar o escuchar la música se gestaron poco a poco en la Edad Media y fueron evolucionando hasta su culminación en el Renacimiento. Por consiguiente, el período que he estudiado brevemente a lo largo de este texto resulta fundamental para entender el pensamiento musical de la modernidad. No en vano, este proceso de subjetividad y musicalidad abre el camino a las teorías modernas que concebirán la música como un lenguaje artístico que privilegia los sentimientos. Diderot declara que la música pura está asociada a las emociones oscuras y a las pasiones tumultuosas que el lenguaje conceptual no es capaz de definir. Se trata, en efecto, de un arte que, en todos los tiempos, sea unido a la palabra o en su versión instrumental, ha dejado sin duda una impresión muy fuerte en el ser humano porque, como sostiene nuestro filósofo, sus efectos son tumultuosos, insconscientes y prelógicos ${ }^{25}$.

RECIBIDO: enero 2017, ACEPTADO: marzo 2017

${ }^{24}$ Ibidem, pp. 158-161.

25 D. Diderot, Oeuvres IV. París, Robert Laffont, 1966, p. 60. 


\section{BIBLIOGRAFÍA}

Agustín de Hipona, Confesiones. Ed. digital basada en la de Espasa Calpe, Madrid, 1983.

Chailley, Jacques, L'École musicale de Saint-Martial de Limoges. París, Les Livres Essentiels, 1960.

Cullin, Olivier, Breve historia de la música en la Edad Media. Paidós, Barcelona, 2005.

Diderot, Denis, Oeuvres IV. París, Robert Laffont, 1966.

Diderot, Denis, Elsobrino de Rameau. Ed. Carmen Roig, Trad. Dolores Grimau, Madrid, Cátedra Letras Universales, 2005.

Duby, Georges, Le Temps des Cathédrales. L’Art et la société 980-1420. París, Gallimard, 1976.

Fubini, Enrico, La estética musical desde la Antigüedad hasta el siglo XX. Madrid, Alianza Música, 1988.

Fubini, Enrico, Estética de la música. Madrid, La Balsa de la Medusa, 2001.

Guido de Arezzo, Micrologus. Ed. Ambrosio M. Amelli, Roma, Desclee, Lefebvre et S. Pont., 1904.

PÉrez, Mariano, El universo de la música. Madrid, Musicalis, 1998.

Platón, Diálogos IV. República. Madrid, Gredos, 1988.

Reti, Rudolph, Tonality in Modern Music. Nueva York, Collier Books, 1962.

Rousseau, Jean-Jacques, Essai sur les origines des langues. CEuvres Complètes V, París, La Pléiade, 1995.

Rowell, Lewis, Introducción a la filosofía de la música. Madrid, Gedisa, 1990.

Strubel, Armand (trad.), Le Roman de Fauvel. París, Coll. Lettres Gothiques, Le Livre de Poche, 2012.

Triay, Josep Pascual, Guía Universal de la Música. Colección. Musica ma non Troppo, Barcelona, Robinbook, 2008.

Zink, Michel, «Musique et subjectivité. Le passage de la chanson d'amour à la poésie personnelle au XIII $^{\text {ème }}$ siècle». Cahiers de civilisation médiévale, vol. 25, núm. 99-100 (1982), pp. 225-232. 